Davies, A. (1956). J. gen. Microbiol. 14, 109-121

\title{
Invertase Formation in Saccharomyces fragilis
}

\author{
BY A. DAVIES \\ Medical Research Council Unit for Chemical Microbiology, Department of \\ Biochemistry, University of Cambridge
}

SUMMARY: The formation of invertase in Saccharomyces fragilis was studied by the continuous culture technique. Invertase formation was markedly inhibited by glucose in the culture medium at concentrations greater than $0.001 \%(w / v)$, by galactose and lactose at all concentrations tested, and by several other carbon sources. The mean generation time of the organisms and the concentration of ammonia and growth factors had no significant effect on invertase formation. The $\mathrm{pH}$ value of the growth medium modified the amount of enzyme formed. The invertase activity, together with non-enzymic hydrolysis of sucrose by the acidic culture medium, was sufficient to account for the disappearance of the observed amount of sucrose from media containing sucrose.

During the growth of a micro-organism under ordinary culture conditions in a limited volume of medium the growth rate continually changes and the chemical composition of the medium varies as a result of the metabolism of the organism. In such circumstances it is difficult, if not impossible, to assess all the factors which control the enzymic activities of the cells. However, if a steady state could be achieved so that known environmental factors could be kept constant, it would be considerably easier to investigate the effect of each such factor. One way of achieving a culture in a steady state is by use of the continuous culture technique described by Monod (1950) and by Novick \& Szilard $(1950 a, b)$, in which the growth rate is determined by the concentration of one particular constituent of the growth medium. Under such conditions the effects of other constituents on enzymic activity can be studied, uncomplicated by changes in growth rate. Also, by altering the rate of addition of the medium, and hence of the limiting factor, the growth rate can be varied without appreciably affecting the steady state concentration of other substances in the growth medium. Therefore, it should be possible to determine whether growth rate per se has any effect on enzyme formation.

There have been many reports of variations of the enzymic activities of bacterial and yeast cells with growth time. Wooldridge, Knox \& Glass (1936) found that the dehydrogenase activities of several bacterial species were low in 'young' cultures, increased with continued growth and then decreased again. Gale \& Stephenson (1938) reported a similar effect with serine deaminase in Escherichia coli. Gale (1940) found that the activities of the bacterial aminoacid decarboxylases were highest when the culture density was maximal. Similar results were obtained with aspartase in $E$. coli (Gale, 1938) and were shown to be due to a change in the chemical composition of the medium, for when the medium in which a culture had grown was sterilized and re-inoculated, the aspartase was high at all stages of growth. Davies (1953) found that 
when Saccharomyces fragilis was grown in a medium containing $2 \%(\mathrm{w} / \mathrm{v})$ glucose, the invertase activity was low during the early phases of growth but later increased rapidly. When the glucose concentration was increased to $10 \%(\mathrm{w} / \mathrm{v})$, invertase activity was low at all stages of growth. The author concluded from these and other experiments that the presence of glucose in the medium inhibited the formation of invertase. Invertase synthesis was demonstrated in suspensions of washed organisms and was inhibited by glucose and fructose.

The present work describes the effect on invertase formation in Saccharomyces fragilis of certain sugars and other carbon sources. The effects of the mean generation time of the organism, concentrations of ammonium and hydrogen ions and of growth factors have also been studied. Most of this work was carried out by means of the continuous culture technique.

\section{ME'THODS}

The chemostat. Fig. 1 shows the most satisfactory type of chemostat devised for this work. It resembles the chemostat of Novick \& Szilard $(1950 a)$, the main difference being in the aerator and the medium feed. The aerator has the dual functions of aerating and stirring the medium. The flow of air through the aerator was sufficiently great to set up an atomizing action, sucking culture fluid in through the side opening and expelling it together with fresh medium at the base. Standard taper (B 24) ground glass joints at ' $A$ ' and ' $B$ ' enabled the cap and the aerator to be removed to facilitate cleaning; ' $B$ ' also served as the inoculation port. The medium was supplied by a Bayliss and Muller type peristaltic pump (Booth \& Green, 1938) driven from a $\mathbf{0} \cdot 125$ h.p. constant speed induction motor through a train of gears. Alterations in the pumping rate are achieved by changing the gear ratio. The pump rollers and rubber tubing were lubricated with silicone grease. The variation in flow rate with a fixed gear ratio was $\pm 0.5 \%$.

Organisms. Saccharomyces fragilis Jörgensen

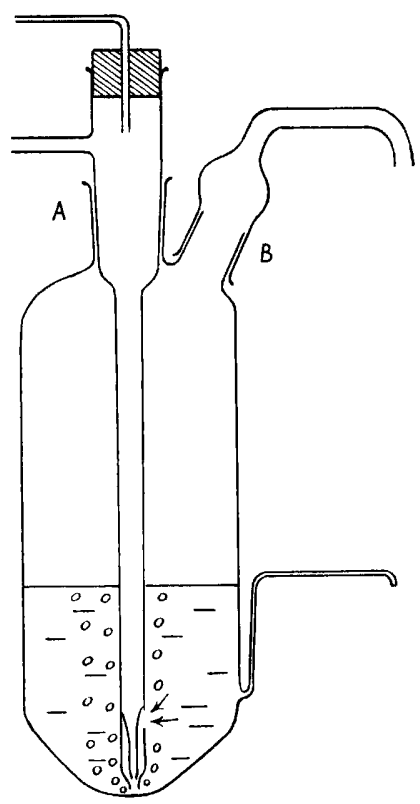

Fig. 1. Diagram of chemostat. was obtained from the Centraalbureau voor Schimmelcultures, Delft, and Torulopsis pulcherrima from the National Collection of Type Cultures, Elstree, in 1946.

Media. The basal medium was that of Davies, Falkiner, Wilkinson \& Peel (1951) with Difco yeast extract replaced by the following amounts of growth factors $(\mu \mathrm{g} . / \mathrm{ml}$.): biotin, 0.01 ; pantothenic acid, nicotinic acid, pyridoxine, thiamine, each $1 \cdot 0$; inositol, 5.0. The basal medium (less thiamine) was 
sterilized by autoclaving. The various carbon sources, glucose, galactose glycerol, sodium acetate, sodium citrate, sodium lactate, and sodium succinate were autoclaved separately; sucrose, lactose and thiamine were sterilized by filtration; ethanol was added as absolute ethanol. The carbon source and thiamine were added aseptically to the basal medium and sterile water added to replace that lost by evaporation.

For chemostat experiments the basal medium was made up in graduated aspirator bottles. For static cultures the medium was dispensed into Roux bottles (150 ml./bottle) and for shaken cultures into $500 \mathrm{ml}$. Erlenmeyer flasks ( $150 \mathrm{ml} . /$ flask). The technique for studying variations in enzymic activity with time of growth was that described by Davies (1953). The inoculum was grown for $\mathbf{2 4} \mathrm{hr}$. in boiling tubes containing the basal medium $+2 \%(\mathrm{w} / \mathrm{v})$ glucose, except for the experiments where growth took place on ethanol, glycerol, sodium acetate, sodium citrate, sodium lactate or sodium succinate, in which cases the glucose was replaced by the respective carbon source. The growth temperature was $30^{\circ}$.

Chemostat procedure. Monod (1950) showed that under steady state conditions of growth in a chemostat, the rate of addition of medium (or washing-out rate) determines the mean generation time of the organisms. The relationship can be expressed as follows: Mean generation time $=\left(\log _{e} 2\right) /$ washing-out rate. The minimum value for the mean generation time is determined by the composition of the medium and the gas phase and increases in the washing-out rate beyond this point result in dilution out of the culture to vanishing point.

In practice the chemostat was connected aseptically to the medium reservoir, the air supply turned on, the chemostat filled with medium and inoculated. After $15-20 \mathrm{hr}$. the addition of medium was begun at the lowest practicable rate $(10 \mathrm{ml} . / \mathrm{hr}$.). It was determined that after a further $24 \mathrm{hr}$., steady state conditions prevailed and the first sample was collected in a receiver cooled in ice. The flow rate was then increased to the value chosen for the next sample which was collected on the following day. This procedure was continued until the lowest practicable mean generation time of $1.5 \mathrm{hr}$. was attained.

Organism suspensions. The yeast was centrifuged from the growth medium, washed twice with distilled water and re-suspended in distilled water. Suspension density was determined by drying a sample at $105^{\circ}$ to constant weight. This procedure was adopted because it was found that the ratio of turbidity to dry weight could vary over a twofold range depending on how the yeast was grown.

Invertase activity was estimated by the method of Davies (1953), which uses cetyltrimethylammonium bromide. The unit of activity has been defined as the amount of enzyme which hydrolyses $1 \mu$ mole sucrose in $1 \mathrm{hr}$. at $\mathbf{2 5}^{\circ}$. From six replicate samples collected from a chemostat running at a fixed flow rate it was found that the coefficient of variation was less than $5 \%$ when the invertase activity was greater than $100 \mathrm{units} / \mathrm{mg}$. When the activity was low ( $<2$ units/mg.) the absolute variation between replicate samples was less than 0.5 unit $/ \mathrm{mg}$. 
Analysis of growth media. Ammonia was determined by steam distillation in a micro-distillation apparatus (Markham, 1942) followed by nesslerization (Folin \& Wu, 1919). Sugars were determined on 0.04-1.8 ml. samples by fermentation in Warburg manometers according to the method of Reithel (1951) modified by increasing the concentration of sodium azide to $1.3 \times 10^{-3} \mathrm{M}$. Yeast was grown for $24 \mathrm{hr}$. in Roux bottles containing $150 \mathrm{ml}$. of the basal medium of Davies et al. (1951) and an appropriate sugar at a concentration of $\mathbf{2} \%(\mathrm{w} / \mathrm{v})$. The yeast was harvested as described above and suspended in $0 \cdot 17$ m-potassium phosphate buffer $(\mathrm{pH} 6 \cdot 0)$ to give a cell density of c. $100 \mathrm{mg} . / \mathrm{ml}$. Sodium azide was added to a concentration of $4 \times 10^{-3} \mathrm{M}$ and the preparation was shaken for $2 \mathrm{hr}$. at $25^{\circ}$ to eliminate endogenous fermentation. Each manometer cup contained $1 \mathrm{ml}$. of this preparation in a final fluid volume of $3 \mathrm{ml}$. Carbon dioxide evolution at $\mathrm{pH} 6.0$ was $95-98 \%$ of the theoretical 2 mole $\mathrm{CO}_{2} /$ mole hexose for glucose, sucrose and lactose, and $92-95 \%$ for galactose.

For determination of glucose and sucrose, Saccharomyces fragilis was grown on a medium containing glucose. For determination of galactose and lactose $S$. fragilis was grown on a medium containing galactose. For determination of invert sugar in cultures containing sucrose Torulopsis pulcherrima was grown on a medium containing glucose.

Chemicals. Kerfoot's Biochemical Reagent Sugars were used throughout; other chemicals were of analytical quality.

\section{RESULTS}

\section{Invertase formation during growth in glucose media in shaken flasks}

The change in invertase content of the cells with time of growth under various conditions is shown in Fig. $2 a, b$. Curves marked $\boldsymbol{A}$ show invertase formation and growth in a medium containing an initial concentration of $1.5 \%(\mathrm{w} / \mathrm{v})$ glucose, $352 \mathrm{mg}$. ammonia-N/l. and $20 \%$ of the standard amount of growth factors. The invertase content of the cells remained low during the greater part of growth and then rose rapidly to high values. This rise in activity was concurrent with the disappearance of glucose from the medium. For curves marked $B$ the medium initially contained $0 \cdot 1 \%(\mathrm{w} / \mathrm{v})$ glucose. Growth ceased earlier and at a lower cell density than in the previous case. The invertase activity was again low in the early phases of growth. Curves $C$ and $D$ (Fig. 2b) show the effect of decreasing the amount of nitrogen in the medium; in both cases growth ceased before glucose was fully utilized and the invertase activity was low throughout the experiment. Growth started at approximately the same rate in both cases, but the final yield of organisms was lower in the medium containing the smaller amount of nitrogen. Curves $D$ and $E$ show the effect of alterations in the amount of growth factors, while glucose and nitrogen are kept constant. The growth curves were almost identical, but whereas in $D$ the invertase content remained low, with the smaller concentration of growth factors (curve $E$ ) glucose utilization continued after growth ceased and invertase activity increased concomitantly. The reason for this is not understood. 


\section{Invertase formation during growth in the chemostat}

Effect of glucose concentration and mean generation time. When the yeast was grown in a chemostat supplied with medium initially containing $9.5 \%(\mathrm{w} / \mathrm{v})$ glucose, $105 \mu \mathrm{g}$. ammonia- $\mathrm{N} / \mathrm{ml}$. and standard concentrations of growth factors, the glucose concentration in the culture became steady at approximately $8 \%(\mathrm{w} / \mathrm{v})$, the nitrogen concentration at approximately $20 \mu \mathrm{g} . / \mathrm{ml}$. and

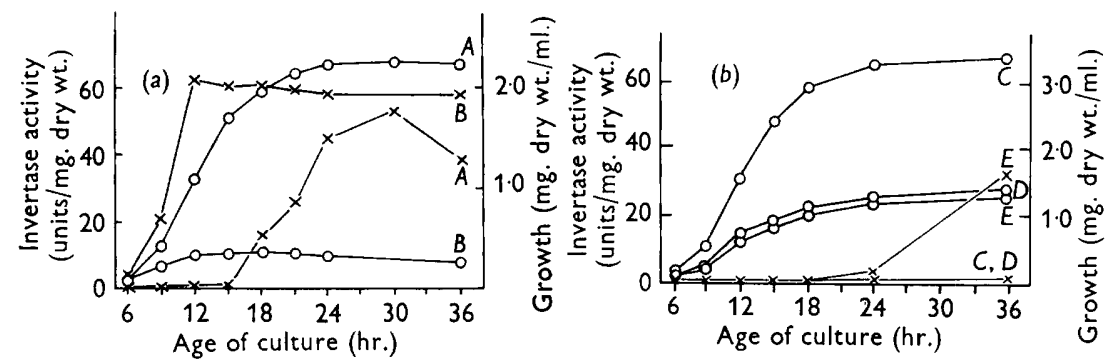

Fig. 2. The effect on invertase content of growth for different periods of time in media containing various amounts of glucose, nitrogen and growth factors. $\times-\times$, invertase activity; $\mathrm{O}-\mathrm{O}$, culture density. The glucose concentrations in the cultures at the different times are shown in the table. Curve $A: 1 \cdot 5 \%(\mathrm{w} / \mathrm{v})$ glucose, $352 \mathrm{mg}$. ammonia$\mathrm{N} / 1 ., 20 \%$ of standard growth factors. Curve $B: 0.1 \%(\mathrm{w} / \mathrm{v})$ glucose, otherwise as curve $A$. Curve $C: 2.0 \%(\mathrm{w} / \mathrm{v})$ glucose, $352 \mathrm{mg}$. ammonia-N/l., standard amounts of growth factors, Curve $D: 105 \mathrm{mg}$. ammonia-N/l., otherwise as curve $C$. Curve $E$ : $20 \%$ of standard growth factors, otherwise as curve $D$.

Residual glucose $(\%, \mathrm{w} / \mathrm{v})$ at various times (hr.)

\begin{tabular}{cllllllll} 
Medium & \multicolumn{1}{c}{} & \multicolumn{1}{c}{9} & 12 & 15 & 18 & 24 & 36 \\
$A$ & 1.2 & 1.0 & 0.64 & 0.24 & 0.03 & Nil & Nil \\
$B$ & 0.05 & 0.01 & Nil & Nil & Nil & Nil & Nil \\
$C$ & 1.8 & 1.6 & 1.3 & 0.55 & 0.26 & 0.15 & 0.14 \\
$D$ & 1.8 & 1.7 & 1.5 & 1.4 & 1.3 & 1.2 & 1.2 \\
$E$ & 1.8 & 1.7 & 1.6 & 1.4 & 1.2 & 0.57 & Nil
\end{tabular}

the invertase activity of the resultant organisms was less than $0 \cdot 6 \mathrm{unit} / \mathrm{mg}$. at all values of the mean generation time. Low degrees of activity were also observed when the supplied medium contained $2 \%(\mathrm{w} / \mathrm{v})$ glucose; in this case the glucose concentration in the culture was always greater than $0.5 \%(\mathrm{w} / \mathrm{v})$; the nitrogen concentration was less than $3 \mu \mathrm{g}$. $/ \mathrm{ml}$. for all flow rates except that corresponding to a mean generation time of $1.6 \mathrm{hr}$. when it rose to $7 \mu \mathrm{g} . / \mathrm{ml}$.

Fig. 3 shows the invertase activities and culture glucose concentrations for growth in media initially containing $1 \cdot 0,0.5$ and $0.25 \%(w / v)$ glucose. In these cases the activity varied with the mean generation time, but could also be correlated with the glucose concentrations in the cultures. In Fig. 4, which is compiled from the results of a large number of experiments, the invertase activity is plotted against the logarithm of the glucose concentration in the culture for mean generation times of 3 and $10 \mathrm{hr}$. The two curves are substantially the same, showing that the rate of cell division has little effect on 
the biosynthesis of invertase under these conditions. It would appear that invertase formation only occurs to a significant extent in media containing less than $0.01 \%(w / v)$ glucose.

Effect of growth factors and nitrogen concentration. Biotin, nicotinic acid and pantothenic acid are essential for growth of this strain of Saccharomyces fragilis; inositol, pyridoxine and thiamin are stimulatory (Bigger, 1952). It is possible to devise conditions in which nitrogen and glucose are in excess; this

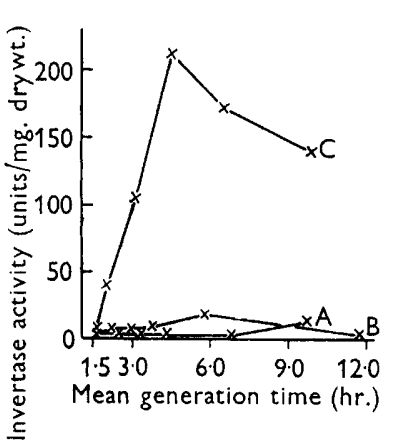

Fig. 3

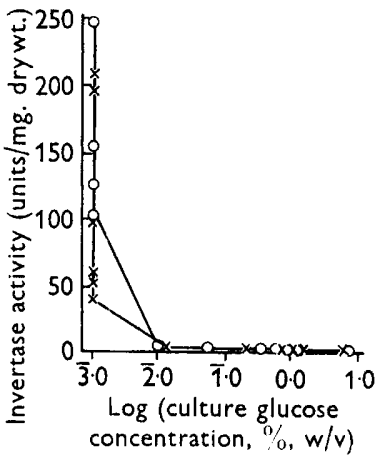

Fig. 4

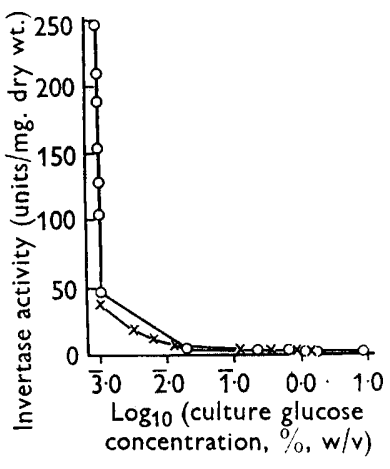

Fig. 5

Fig. 3. Variation of invertase activity with mean generation time. Initial glucose concentrations $(\% \mathrm{w} / \mathrm{v})$ in media: $A, 1 \cdot 0 ; B, 0.5 ; C, 0 \cdot 25$.

Fig. 4. Effect of culture glucose concentration and mean generation time on invertase activity. $x-x$, cells grown with a mean generation time of $3 \mathrm{hr}$; $\bigcirc-\bigcirc$, cells grown with a mean generation time of $10 \mathrm{hr}$. The limit of sensitivity of the sugar analysis procedure is $0 \cdot 001 \%$ glucose.

Fig. 5. Effect of culture glucose concentration and nitrogen concentration on invertase activity. $\times-x$, culture containing $<2 \mu \mathrm{g}$. ammonia- $\mathrm{N} / \mathrm{ml}$.; $\mathrm{O}-\mathrm{O}$, culture containing $>10 \mu \mathrm{g}$. ammonia- $\mathrm{N} / \mathrm{ml}$.

can be done by making one or other growth factor limiting. Under these conditions it was found that neither variation in nitrogen concentration nor in the nature of the growth factor which was limiting, had any appreciable effect on the invertase activity. The overriding influence of the steady state glucose concentration in the culture is again shown by Fig. 5 in which the logarithm of the culture glucose concentration is plotted against the invertase activity for the two cases $(a)$ where the nitrogen concentration is less than $2 \mu \mathrm{g} . / \mathrm{ml}$.; (b) where it is greater than $10 \mu \mathrm{g} . / \mathrm{ml}$. The two curves are almost identical at glucose concentrations greater than $0.001 \%(w / v)$, which is the limit of sensitivity of the sugar determination procedure. This demonstrates clearly the absence of any significant effect of nitrogen concentration, irrespective of the nature of the growth-limiting substance.

Effect of $\mathrm{pH}$ value of growth medium. The $\mathrm{pH}$ value of the culture in the chemostat varied between $\mathrm{pH} \mathbf{2 \cdot 6}$ and $\mathbf{3} \cdot 4$, depending on the concentration of sugar in the medium. By adding appropriate amounts of potassium hydroxide to the medium it was possible to grow the yeast over a wide range of $\mathrm{pH}$ values 
in media of otherwise similar composition. When the basal medium contained $0.1 \%(\mathrm{w} / \mathrm{v})$ glucose and the mean generation time was $4 \mathrm{hr}$., the potential invertase activity (i.e. activity measured at the optimal $\mathrm{pH}$ value for invertase action) varied with $\mathrm{pH}$ value as shown in Fig. 6, curve $A$. Between $\mathrm{pH} 3.5$ and $7 \cdot 7$ there was no detectable glucose in the culture; between $\mathrm{pH} 7 \cdot 7$ and 8.3 the glucose increased to $0.014 \%(\mathrm{w} / \mathrm{v})$. The effective activity (see Gale \& Epps, 1942 ) is also plotted, and was found to decrease steadily as the $\mathrm{pH}$ value increased from $3 \cdot 5$ to $8 \cdot 3$ (curve $B$ ).

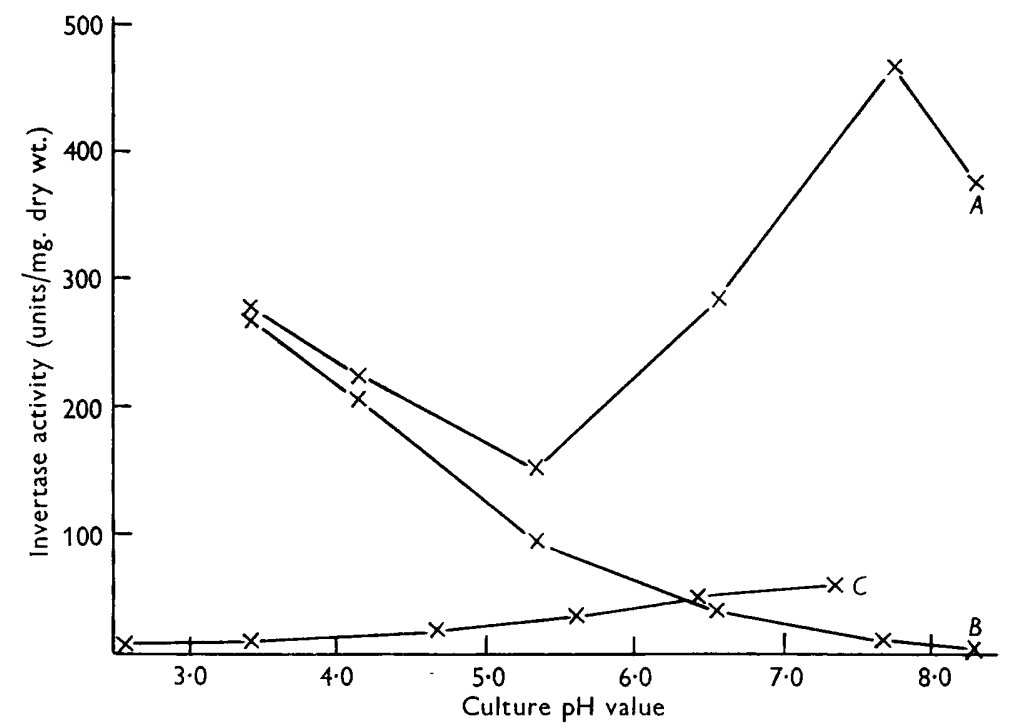

Fig. 6. Effect of culture $\mathrm{pH}$ value on invertase content. Curve $\boldsymbol{A}$ : potential activity of cells grown with a mean generation time of $4.0 \mathrm{hr}$. in a medium initially containing $0.1 \%$ glucose. Curve $B$ : effective activity of the aforementioned cells. Curve $C$ : potential activity $\times 10$ of cells grown with a mean generation time of $3.5 \mathrm{hr}$. in a medium initially containing $2.0 \%$ glucose. The potential activities were determined at the optimum $\mathrm{pH}$ value (3.7) and a correction made for acid hydrolysis in the test system.

When the yeast was grown in the basal medium plus $2 \%(\mathrm{w} / \mathrm{v})$ glucose at a mean generation time of $3.5 \mathrm{hr}$., the potential activity increased from $0 \cdot 6$ unit/mg. at $\mathrm{pH} \mathrm{2 \cdot 6}$ to 6 units/mg. at $\mathrm{pH} 7 \cdot 6$ (Fig. 6, curve $C$ ), while the effective activity was approximately constant over the whole range.

\section{Media containing sugars other than glucose}

Sucrose. Fig. 7 shows that when growth occurred in a medium containing an excess of sucrose $(1 \%, \mathrm{w} / \mathrm{v}$, curve $A)$ the invertase activity was low $(0 \cdot 5-2 \cdot 0$ units/mg.). Since the culture was found to contain both sucrose $(0.3-0.6 \%, \mathrm{w} / \mathrm{v})$ and invert sugar $(0.02-0.05 \%, \mathrm{w} / \mathrm{v})$, it was impossible to decide whether sucrose itself exerts any specific effect on the invertase activity. When the yeast was grown in a $\mathbf{0} \cdot \mathbf{2} \%(\mathrm{w} / \mathrm{v})$ sucrose medium (curve $\boldsymbol{B}$ ) the invertase activity was high. Although in this case the invertase activity 
varied with mean generation time, it could again be correlated with changes in the sugar (mostly invert sugar) concentration in the culture (curve $C$ ). The growth obtained in both concentrations of sucrose was approximately the same as that obtained in corresponding media containing glucose.

When the yeast is grown in an excess of sucrose it is possible to compare the disappearance of sucrose from the medium with the maximum possible disappearance calculated on the basis of the observed invertase activity. The results are given in Table 1 . It is evident that the sucrose disappearance can

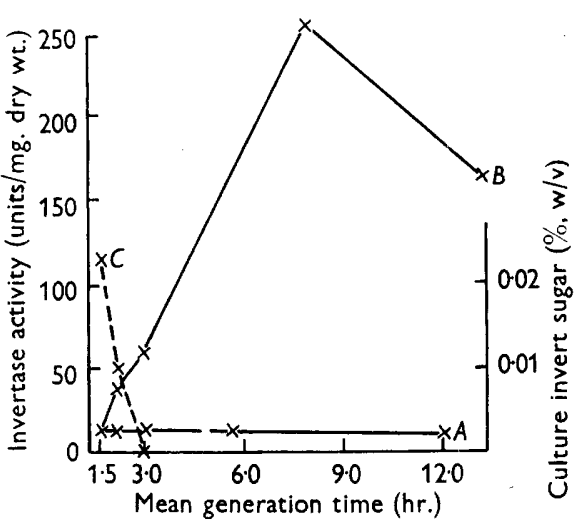

Fig. 7

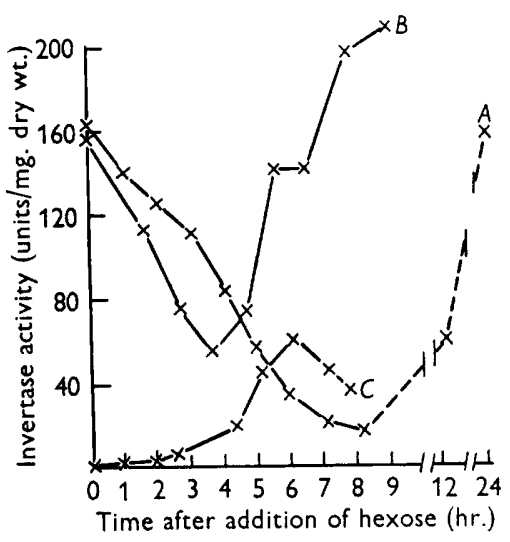

Fig. 8

Fig. 7. Effect of growth at different mean generation times in media containing sucrose. Curve $A$, invertase activities $\times 10$ during growth in a medium initially containing $1 \%(w / v)$ sucrose. Curve $B$, invertase activities during growth in a medium initially containing $0.2 \%$ sucrose. Curve $C$, culture invert sugar concentrations corresponding to curve $B$.

Fig. 8. Curves $A$ and $B$ : effect of adding galactose $(1 \%, \mathrm{w} / \mathrm{v}$, curve $A ; 0 \cdot 1 \%$, w/v, curve $B$ ) to cultures growing on $0.1 \%(w / v)$ glucose medium with a mean generation time of $3.5 \mathrm{hr}$. Curve $C$ : effect of adding glucose $(1.0 \%, \mathrm{w} / \mathrm{v})$ to a culture growing on $0.2 \%$, $(\mathrm{w} / \mathrm{v})$ galactose medium with a mean generation time of $3 \cdot 7 \mathrm{hr}$., the activities are shown times ten for clarity.

Table 1. Correlation between observed sucrose disappearance in media containing an excess of sucrose and that calculated from the invertase content

Enzymic hydrolysis measured at $\mathrm{pH}$ value and temperature of culture and at optimal sucrose concentration. Resulting values were then corrected to allow for the fact that the culture sucrose concentration was suboptimal, the correction factor being $\mathbf{0 \cdot 9}$.

Expt.

pH value of culture

Sucrose disappearance due to spontaneous hydrolysis at culture $\mathrm{pH}$ value (mg./ml.)

Sucrose disappearance due to enzymic hydrolysis (mg./ml.)

Observed sucrose disappearance (mg./ml.)

$\left.\begin{array}{lll}\text { I } & \text { II } & \text { III } \\ 3 \cdot 15 & \left.\begin{array}{l}3 \cdot 19 \\ 0.2 \\ 1.3\end{array}\right\} \begin{array}{l}3 \cdot 12 \\ 1.5\end{array} & 0.2 \\ 1.5 & 1.7\end{array}\right\}$


be accounted for by the invertase content of the yeast provided due allowance is made for non-enzymic hydrolysis of sucrose under the acidic conditions of the medium.

Lactose or galactose. In Table 2, the invertase activity of yeast grown in various concentrations of lactose or galactose is compared with that for glucose media. It will be seen that the response is different in that high degrees of activity were not obtained in low concentrations of lactose or galactose, in fact, on increasing the galactose concentration to $2 \%(\mathrm{w} / \mathrm{v})$ the invertase activity rose fivefold to tenfold. Similar results were obtained for mean generation times between $1 \cdot 6$ and $10 \mathrm{hr}$.

Table 2. Invertase activities of Saccharomyces fragilis grown in media containing various sugars

Yeast grown in chemostat at a mean generation time of $3 \cdot 3 \mathrm{hr}$. Invertase activities expressed as units/mg. dry weight.

Concentration of
sugar in growth
medium $(\%, \mathrm{w} / \mathrm{v})$
$2 \cdot 0$
1.0
0.2

\begin{tabular}{ccc}
\multicolumn{2}{c}{ Invertase activities for growth on } \\
$\overbrace{\text { Glucose }}^{\text {Galactose }}$ & Lactose \\
$0 \cdot 2-0 \cdot 6$ & $4 \cdot 0$ & - \\
$0 \cdot 2-0 \cdot 6$ & $0 \cdot 6$ & $1 \cdot 4$ \\
200 & $0 \cdot 2$ & $0 \cdot 7$
\end{tabular}

Mixtures of glucose and galactose. The effect of adding galactose to an exponentially growing culture which had a high invertase activity was demonstrated by the following experiments. From a culture growing with a mean generation time of $3.5 \mathrm{hr}$. in the basal medium $+0.1 \%(\mathrm{w} / \mathrm{v})$ glucose a $10 \mathrm{ml}$. sample was collected and then galactose was added directly to the culture to give a final concentration of $1.0 \%$ in the first experiment and $0.1 \%(\mathrm{w} / \mathrm{v})$ in the second experiment. Further samples were collected at intervals and their invertase contents determined. There was an immediate and rapid decrease in the invertase activity followed by a rise (Fig. 8, curves $A$ and $B$ ). The decrease was greater with $1 \%(\mathrm{w} / \mathrm{v})$ galactose and the activity was low for a longer time, but the rate of decline in activity was greater with $0.1 \%$ galactose.

The effect of adding glucose (final concentration $1.0 \%(w / v)$ ) to a culture growing exponentially with a mean generation time of $3.7 \mathrm{hr}$. on a $0 \cdot 2 \%(\mathrm{w} / \mathrm{v})$ galactose medium is also shown in Fig. 8, curve $C$. A rise in activity to 6 units/mg. was observed $6 \mathrm{hr}$. after addition of glucose. Table 3 shows the

Table 3. Effect on invertase content of growth in media containing various amounts of glucose and galactose

Saccharomyces fragilis grown in chemostat at a mean generation time of $3 \cdot 3 \mathrm{hr}$. In all cases the culture hexose concentration was less than $0.001 \%(w / v)$.

$\begin{array}{lcccc}\begin{array}{l}\text { Initial glucose } \\ \text { concentration }(\%, \mathrm{w} / \mathrm{v})\end{array} & 0.20 & 0.18 & 0 \cdot 15 & 0.11 \\ \begin{array}{c}\text { Initial galactose } \\ \text { concentration }(\%, \mathrm{w} / \mathrm{v})\end{array} & \text { Nil } & 0.02 & 0.05 & 0.09 \\ \begin{array}{c}\text { Invertase activity } \\ \text { (units/mg. dry wt.) }\end{array} & 190 & 127 & 36 & 6.5\end{array}$


effect on invertase formation of growth in a medium containing various amounts of glucose and galactose and demonstrates clearly the inhibitory effect of galactose under these conditions.

Growth in other carbon sources. Under aerobic conditions Saccharomyces fragilis used arabinose, fructose, glucose, galactose, lactose, mannose, sucrose, raffinose, xylose, ethanol, glycerol, acetate, citrate, lactate or succinate for growth. Ribose, sorbose, dulcitol, mannitol, sorbitol and sodium potassium tartrate were not utilized. Except for the sugars, and for lactate for which the minimum mean generation time was $3.5 \mathrm{hr}$., the minimum mean generation

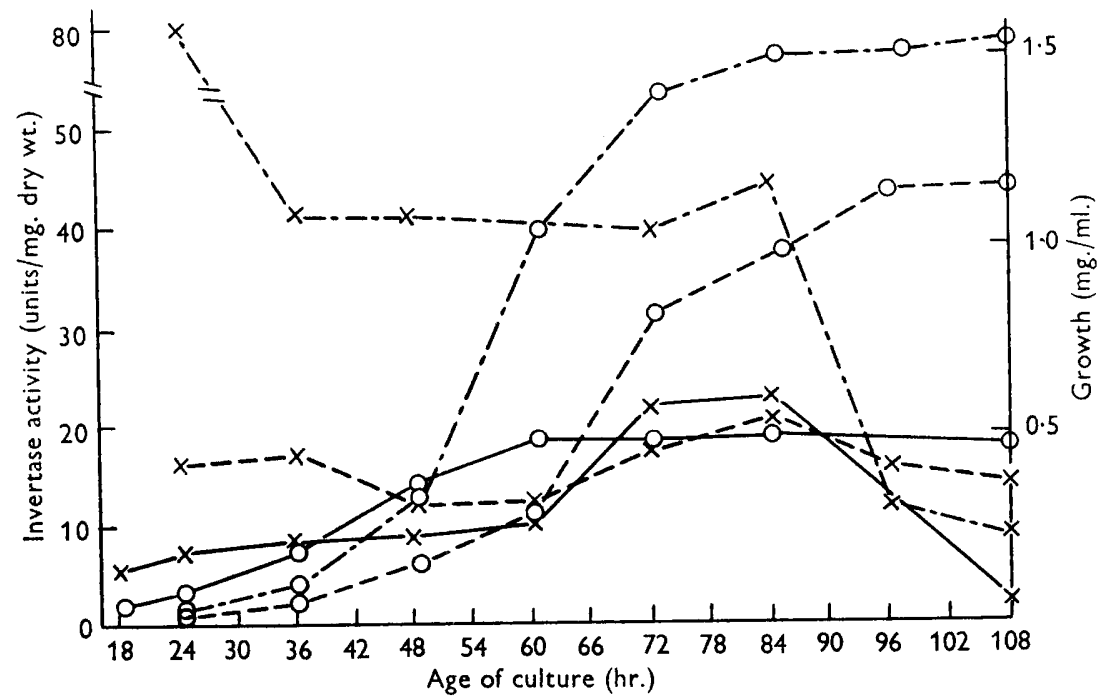

Fig. 9. Effect of 'age of culture' on the invertase content of $S$. fragilis grown on basal medium containing non-carbohydrate carbon sources. $x$, invertase activities; $O$, culture density; - - , basal medium plus $1 \%(w / v)$ sodium succinate; - . - , basal medium plus $1.0 \%(\mathrm{w} / \mathrm{v})$ ethanol : $\cdot-\cdot-\cdot$, basal medium plus $1 \%(\mathrm{w} / \mathrm{v})$ glycerol.

time exceeded $5 \mathrm{hr}$. and in some cases (acetate, citrate) was 8-12 hr. It was not practicable to use the chemostat for such low growth rates. Cultures were therefore grown in Roux bottles on basal medium containing $1 \%$ of various substances as carbon sources and the invertase activity determined after various periods of growth.

Acetate, citrate or succinate gave similar results up to the time when growth ceased. In the earlier stages of growth the invertase activity was about ten times that in a $1 \%(\mathrm{w} / \mathrm{v})$ glucose medium, the activity then increased to a maximum towards the end of growth. With succinate, but not acetate or citrate, there was a fall in invertase activity shortly after growth had ceased (Fig. 9).

Ethanol at a concentration of $1 \%(\mathrm{v} / \mathrm{v})$ gave an invertase activity of c. 15 units/mg. which showed little variation throughout growth.

With glycerol invertase activity was high (80 units/mg.) at the start of the exponential phase of growth but it rapidly fell to about 40 units/mg. at which 
level it remained constant until after growth ceased when there was a further fall to 9 units/mg. (Fig. 9).

With lactate the invertase activity remained at a low level $(\mathbf{0} \cdot \mathbf{1 - 1} \cdot \mathbf{0} \mathrm{unit} / \mathrm{mg}$. throughout the growth period.

\section{DISCUSSION}

The formation of many enzymes is suppressed by the presence of glucose in the growth medium (Gale, 1943). The effect on invertase formation, however, is wider than an inhibition by glucose, for if the invertase activity in the presence of low concentrations of glucose is taken as the uninhibited value, then all carbon sources tested are inhibitory, though with some, such as raffinose (Davies, 1953) and glycerol, the inhibition is small. The type of response shown by the yeast depends on both the nature and the concentration of the carbon source. For instance, the response to galactose differs from that to glucose; the highest activities (about $2 \%$ of that observed in a medium containing low concentrations of glucose) are found in media initially containing $2 \%(\mathrm{w} / \mathrm{v})$ galactose, while lower invertase activities are observed when the galactose concentration is reduced. Yeast which has grown on a medium containing an excess of sucrose has a low invertase activity. At first sight this would seem to indicate that invertase formation is suppressed by sucrose. However, the low activity can be accounted for by the presence of low concentrations of invert sugar in the culture. Because of this, it is impossible under the conditions used to decide whether sucrose has any inhibitory or stimulatory action on invertase formation. The observed low concentrations of invert sugar in these cultures are in accordance with the hypothesis of Hestrin \& Lindegren (1952), that biosynthesis of carbohydrases in yeast continues until the rate of production of hexose by hydrolysis of oligosaccharides slightly exceeds the rate of utilization of the hexose, the accumulating hexose then inhibiting further enzyme formation. The fact that, after allowance had been made for acid hydrolysis in the culture, sucrose disappearance in these cultures agreed closely with that calculated on the basis of the invertase activity of the organisms in washed suspension, would suggest that the sole pathway of sucrose metabolism is via hydrolysis to invert sugar.

Davies (1953) found that with sucrose as energy source synthesis of invertase by washed suspensions of Saccharomyces fragilis proceded optimally between pH $4 \cdot 0$ and $5 \cdot 0$, the optimum $\mathrm{pH}$ value for enzyme action being approximately 4.0. However, the same relationship was observed when glucose was the energy source, in which case the energy supply is not dependent on the activity of the enzyme. In growing cultures the formation of invertase shows a different response to $\mathrm{pH}$ value, the potential activity of the yeast grown in a $0.1 \%(\mathrm{w} / \mathrm{v})$ glucose medium being at a minimum when the culture $\mathrm{pH}$ value is $\mathbf{5 . 4}$. The activity increases as the $\mathrm{pH}$ value is reduced to 3.5 or increased to 7.7. Between $\mathrm{pH} 7 \cdot 7$ and $8 \cdot 3$ the activity decreases again, probably due to an increase in the glucose concentration in the culture over this range. The optimal effective activity is obtained with a culture at $\mathrm{pH}$ 3.5. Since the invertase 
activity of organisms grown in a $2 \%(\mathrm{w} / \mathrm{v})$ glucose medium over a wide range of $\mathrm{pH}$ values is low, it would appear that the inhibitory effect of high concentrations of glucose occurs at all $\mathrm{pH}$ values.

In the introduction it was stated that by use of the continuous culture technique it should be possible to assess the part played by changes in the rate of division and in the concentration of various nutrients on the invertase content of the organisms. It has now been shown that the rate of division and the concentration of ammonium ions and growth factors in the culture have no significant effect on the invertase content of the organisms under the conditions employed. As the $\mathrm{pH}$ values of the cultures $(2 \cdot 6-3 \cdot 4$, depending on sugar concentration) normally shows little change, this factor also has little effect on the invertase content, though, as described above, large changes in $\mathrm{pH}$ value have a marked effect. The main factor which controls the invertase content of Saccharomyces fragilis in media containing glucose is the glucose concentration.

The author wishes to express his thanks to the Medical Research Council for a Scholarship for Training in Research Methods, and to Dr R. Davies and Dr E. F. Gale, F.R.S., for much helpful advice and encouragement.

\section{REFERENCES}

Bigger, L. C. (1952). Amino-acid metabolism in Saccharomyces fragilis. Ph.D. Thesis, Cambridge.

Воотн, V. H. \& GreEn, D. E. (1938). A wet crushing mill for micro-organisms. Biochem. J. 32, 855 .

Davies, R. (1953). Enzyme formation in Saccharomyces fragilis. 1. Invertase and raffinase. Biochem. J. 55, 484.

Davies, R., Falkiner, E. A., Wilkinson, J. F. \& Peel, J.L. (1951). Ester formation in yeasts. 1. Ethyl acetate formation by Hansenula species. Biochem. J. 49, 58.

Folin, O. \& Wu, H. (1919). A system of blood analysis. J. Biol. Chem. 38, 81.

Gale, E. F. (1938). Factors influencing bacterial deamination. 3. Aspartase II. Its occurrence in and extraction from Bacterium coli and its activation by adenosine and related compounds. Biochem. J. 32, 1583.

Gale, E. F. (1940). Production of amines by bacteria. 1. Decarboxylation of aminoacids by strains of Bacterium coli. Biochem. J. 34, 392.

Gale, E. F. (1943). Factors influencing the enzymic activities of bacteria. Bact. Rev. $7,139$.

Gale, E. F. \& Epps, H. M. R. (1942). Effect of the pH of the medium during growth on the enzymic activities of bacteria (Escherichia coli and Micrococcus lysodeikticus) and the biological significance of the changes produced. Biochem. J. 36, 600 .

Gale, E. F. \& Stephenson, M. (1938). Factors influencing bacterial deamination. 2. Factors influencing the activity of DL-serine deaminase in Bacterium coli. Biochem. J. 32, 392.

Hestrin, S. \& LinDegren, C. C. (1952). Carbohydrases in Saccharomyces haploid stocks of defined genotype. II. Gene controlled induction of glucosidases by $\alpha$-glucosides. Arch. Biochem. Biophys. 38, 317.

Markham, R. (1942). A stream distillation apparatus suitable for micro-Kjeldahl analysis. Biochem. J. 36, 790. 
Monod, J. (1950). La technique de culture continue. Théorie et applications. Ann. Inst. Pasteur, 79, 390.

Novick, A. \& Szilard, L. (1950a). Description of the chemostat. Science, 112, 715.

Novick, A. \& Szilard, L. (1950b). Experiments with the chemostat on spontaneous mutations of bacteria. Proc. nat. Acad. Sci., Wash., 36, 708.

ReITHel, F. J. (1951). Fermentation by yeasts in the presence of azide. Northw. Sci. $25,38$.

Wooldridge, W. R., Knox, R. \& Grass, V. (1936). Variability in the activity of bacterial enzymes. I. The effect of the age of the culture. Biochem. J. 30, 926 .

(Received 2 August 1955) 